\title{
Increasing abdominal pressure with and without PEEP: effects on intra-peritoneal, intra-organ and intra-vascular pressures
}

\author{
Stephan M Jakob*1, Rafael Knuesel1, Jyrki J Tenhunen², Richard Pradl² and Jukka Takala1
}

\begin{abstract}
Background: Intra-organ and intra-vascular pressures can be used to estimate intra-abdominal pressure. The aim of this prospective, interventional study was to assess the effect of PEEP on the accuracy of pressure estimation at different measurement sites in a model of increased abdominal pressure.

Methods: Catheters for pressure measurement were inserted into the stomach, urinary bladder, peritoneal cavity, pulmonary artery and inferior vena cava of 12 pigs. The pressures were recorded simultaneously at baseline, during 10 $\mathrm{cm} \mathrm{H}_{2} \mathrm{O}$ PEEP, external abdominal pressure (7 kg weight) plus PEEP, external abdominal pressure without PEEP, and again under baseline conditions.

Results (mean \pm SD): PEEP alone increased diastolic pulmonary artery and inferior vena cava pressure but had no effect on the other pressures. PEEP and external abdominal pressure increased intraperitoneal pressure from $6 \pm 1 \mathrm{~mm}$ $\mathrm{Hg}$ to $9 \pm 2 \mathrm{~mm} \mathrm{Hg}$, urinary bladder pressure from $6 \pm 2 \mathrm{~mm} \mathrm{Hg}$ to $11 \pm 2 \mathrm{~mm} \mathrm{Hg}(p=0.012)$, intragastric pressure from $6 \pm 2 \mathrm{~mm} \mathrm{Hg}$ to $11 \pm 2 \mathrm{~mm} \mathrm{Hg}$ (all $p \leq 0.001$ ), and inferior vena cava pressure from $11 \pm 4 \mathrm{~mm} \mathrm{Hg}$ to $15 \pm 4 \mathrm{~mm} \mathrm{Hg}$ ( $p$ $=0.01)$. Removing PEEP and maintaining extraabdominal pressure was associated with a decrease in pulmonary artery diastolic but not in any of the other pressures. There was a significant correlation among all pressures. Bias $(-1 \mathrm{~mm} \mathrm{Hg})$ and limits of agreement ( 3 to $-5 \mathrm{~mm} \mathrm{Hg}$ ) were similar for the comparisons of absolute intraperitoneal pressure with intra-gastric and urinary bladder pressure, but larger for the comparison between intraperitoneal and inferior vena cava pressure $(-5,0$ to $-11 \mathrm{~mm} \mathrm{Hg}$ ). Bias $(0$ to $-1 \mathrm{~mm} \mathrm{Hg}$ ) and limits of agreement ( 3 to $-4 \mathrm{~mm} \mathrm{Hg}$ ) for pressure changes were similar for all comparisons
\end{abstract}

Conclusions: Our data suggest that pressure changes induced by external abdominal pressure were not modified by changing PEEP between 0 and $10 \mathrm{~cm} \mathrm{H}_{2} \mathrm{O}$.

\section{Background}

Intraabdominal hypertension (IAH), a sustained increase in intraabdominal pressure (IAP) above $12 \mathrm{mmHg}$, and abdominal compartment syndrome (ACS), a sustained increase in IAP above $20 \mathrm{mmHg}$ with new-onset organ failure [1,2], are highly prevalent in critically ill patients, especially in those with a high body mass index, massive fluid resuscitation, and renal and coagulation impairment [3]. In this context, significant cardiovascular [4], respiratory [5], renal [6], hepatosplanchnic [7-10] and neuro-

* Correspondence: stephan.jakob@insel.ch

1 Department of Intensive Care Medicine, University Hospital (Inselspital) and University of Bern, Bern, Switzerland

Full list of author information is available at the end of the article logic dysfunction [11] with increased mortality have been described [12].

Despite increasing evidence regarding the relevance of IAH and ACS, many intensive care units never measure the intraabdominal pressure (IAP), and no consensus exists on optimal timing of measurement or when decompressive laparotomy should be performed $[13,14]$. The definitions and diagnosis of IAH and ACS depend greatly on the accuracy, reliability and reproducibility of the IAP measurement technique [15], yet clinical measures of elevated IAP such as measuring abdominal girth and assessing the tenseness of the abdomen have low sensitivity and accuracy $[13,16]$, and the direct measurement of IAP is rather invasive, and- with the exception of intra- 
operative measurements during laparoscopic interventions- not feasible in the clinical setting in most cases [17].

Since the abdomen and its contents can be considered primarily fluid in character, and consequently noncompressive, the IAP can be measured in nearly every part of the abdomen [18]. Alternative indirect methods for estimating IAP, such as measuring urinary bladder, inferior vena cava, gastric, intrarectal, and intrauterine pressures, have been used over the years. However, although the intravesical route has evolved as the gold standard [13], the ideal method for measuring intraabdominal pressure has increasingly become a matter of debate [18]. Both Foley manometers and IAP monitors are reliable and reproducible methods of measuring IAP, with low coefficients of variation, especially with increasing IAP [19].

While ACS may decrease lung compliance, increasing PEEP may limit the cranial expansion of the abdominal cavity. Pressure changes on both sides of the diaphragm may lead to alterations in the relationship between lower and upper intraabdominal, and intrathoracic and intraabdominal intravascular pressures [20]. The aim of this study was to assess the relationship between the pressure changes in the urinary bladder, the inferior caval vein, the stomach, and the pulmonary artery with directly measured intraperitoneal pressure changes during a small but clinically significant increase in IAP with and without moderate positive end-expiratory pressure (PEEP). We hypothesized that increased IAP decreases during PEEP release, and that this effect is more pronounced in the upper abdomen and intra-vascularly.

\section{Methods}

This study was approved by the Institutional Animal Care and Use Committee of the University of Kuopio, Finland.

\section{Anesthesia and animal preparation}

Twelve female pigs weighing 34 (27-43) kg (median, range) were deprived of food but had free access to water $12 \mathrm{~h}$ before the experiment. After premedication with atropine $(0.05 \mathrm{mg} / \mathrm{kg})$ and azaperone $(8 \mathrm{mg} / \mathrm{kg}$ intramuscularly), an ear vein was cannulated and thiopental sodium $(5-15 \mathrm{mg} / \mathrm{kg}$ ) was administered intravenously for endotracheal intubation. Anesthesia was maintained with thiopental $(5 \mathrm{mg} / \mathrm{kg} / \mathrm{h})$ and fentanyl $(30 \mathrm{mg} / \mathrm{kg} / \mathrm{h})$ until the end of the surgical procedure, and afterwards with thiopental $(5 \mathrm{mg} / \mathrm{kg} / \mathrm{h})$ and fentanyl $(5 \mathrm{mg} / \mathrm{kg} / \mathrm{h})$ until the end of the experiment.

The animals were ventilated with a volume-controlled ventilator (Servo 900C, Siemens AG, Solna, Sweden) without positive end-expiratory pressure. Fractional inspired $\mathrm{O}_{2}$ concentration was adjusted to reach a target arterial $\mathrm{PO}_{2}$ of $100 \mathrm{mmHg}$. Tidal volume was kept at 10 $\mathrm{ml} / \mathrm{kg}$, and the minute ventilation was adjusted to maintain arterial $\mathrm{PCO}_{2}$ levels between 33 and $45 \mathrm{mmHg}$.

A pulmonary artery catheter (CO Catheter, Edwards Lifesciences, Irvine, CA, USA) was inserted using pressure readings via the right submandibular vein. A femoral artery catheter and a gastric air tonometer with connections to pressure transducers were inserted (Tonometrics, Worcester, MA). Another catheter was inserted into the inferior vena cava via the right internal jugular vein, and its correct position (tip at lower border of liver) was confirmed by ultrasound. The abdominal wall was punctured with an $18 \mathrm{G}$ needle in the right lower abdominal quadrant. Injuries to the gut and intraabdominal organs were avoided by lifting the abdominal wall with two towel clamps. A commercially available $16 \mathrm{G} \times 30 \mathrm{~cm}$ singlelumen intravenous catheter (Arrow International, Reading, PA, USA) was inserted into the peritoneal cavity using a J-shaped guide wire and a dilator. A Foley catheter was placed in the urinary bladder via the urethra. These catheters were also connected to pressure transducers.

During surgery the animals received saline at $5 \mathrm{ml} / \mathrm{kg} /$ h. Additional Ringer's lactate solution and hydroxyethyl starch were administered in equal amounts during surgery to keep the pulmonary artery occlusion pressure between 6 and $12 \mathrm{mmHg}$. The body temperature of the animals was kept at $38 \pm 1^{\circ} \mathrm{C}$ using an operating table heater and warmed fluids. The position of the catheters was checked by palpation and by direct visualization after the experiments had been completed.

\section{Hemodynamic monitoring}

All pressures were measured continuously with quartz pressure transducers and displayed on a multimodular monitor and recorder (AS3, Datex-Ohmeda, Helsinki, Finland). At the same time, the signals were recorded with a computer program (Windaq 1.60; Dataq Instruments Inc., Akron, OH, USA) for later analysis. All pressure transducers were simultaneously zeroed to a level corresponding to the ventral border of the front leg (Figure 1). Heart rate was measured from the electrocardio-

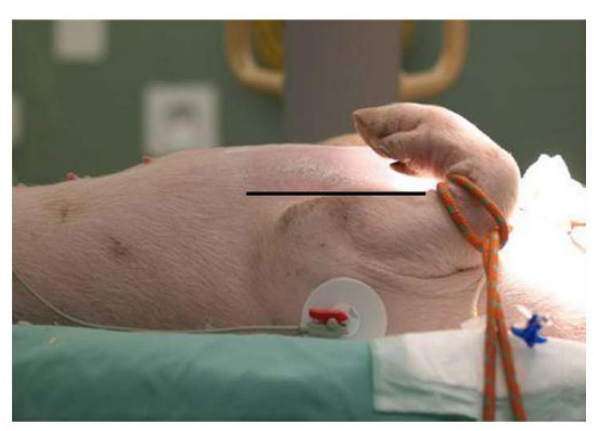

Figure 1 Zero reference for pressure transducers. Black line: zero level. 
gram, which was also continuously monitored. Cardiac output was measured with the thermodilution technique (mean value of three measurements). Central venous blood temperature $\left({ }^{\circ} \mathrm{C}\right)$ was recorded from the thermistor of the pulmonary artery catheter.

\section{Experimental protocol}

After placement of the catheters and hemodynamic stabilization for 30 minutes, the urinary bladder was emptied and refilled with $50 \mathrm{ml}$ of normal saline. Afterwards, baseline values were taken. Next, abdominal and endexpiratory pressures were changed in four non-randomized steps, each lasting approximately 10 minutes: 1) increase in PEEP to $10 \mathrm{~cm} \mathrm{H}_{2} \mathrm{O}$;2) increase in abdominal pressure by applying an external abdominal weight of 7 $\mathrm{kg}$; 3) decrease in PEEP to $0 \mathrm{~cm} \mathrm{H}_{2} \mathrm{O}$; 4) removal of the abdominal weight. Each change in pressure was followed by approximately five minutes of stabilization before the measurements were taken. Artefact-free recordings of two minutes were averaged. At the end of this experiment, the animals were subsequently included in a separate study on hepato-splanchnic blood flow regulation [21].

\section{Statistics}

Statistical analysis was performed with the SPSS software (version 12.01, SPSS Inc., Chicago, IL, USA). Parametric tests were used. Pressures at baseline were compared using one-way ANOVA. ANOVA for repeated measurements was applied for the assessment of pressure changes at the different locations. Effects of PEEP, and of external abdominal pressure with and without PEEP, were com- pared to baseline post-hoc using paired $\mathrm{T}$ tests. The same test was used to assess differences between external abdominal pressure with and without PEEP. The Bonferroni approach was applied to compensate for multiple ( $\mathrm{n}$ $=4$ ) comparisons: for T tests, a p value of 0.0125 was considered significant. To compare the magnitude of pressure changes at the different locations, one-way ANOVA and linear correlation was used. Data are presented by means of Bland-Altman and correlation plots. Bland-Altman statistics were calculated using Microsoft Office Excel 2007 (Microsoft Corporation, Wallisellen, Switzerland).

\section{Results}

In one animal the intraperitoneal pressure did not increase after applying external weight onto the abdomen; consequently this animal was excluded from statistical analysis but an additional experiment was performed. Due to technical reasons or evidence of incorrect placement of the catheters after the experiment, some pressures are missing (inferior vena cava: $\mathrm{n}=2$; stomach: $\mathrm{n}=2$; pulmonary artery: $\mathrm{n}=3$; systemic artery: $\mathrm{n}=2$ ).

\section{Systemic hemodynamics}

Systemic hemodynamics remained stable during the experiment (Table 1).

\section{Absolute pressures at baseline}

At baseline, there were significant differences between pressures at the different measurement sites $(\mathrm{p}<0.001$; Table 2).

Table 1: Systemic hemodynamics and central temperature.

\begin{tabular}{|c|c|c|c|c|c|c|c|}
\hline & Baseline* & PEEP & $\begin{array}{c}\text { PEEP+external } \\
\text { abdominal pressure* }\end{array}$ & $\begin{array}{c}\text { External } \\
\text { abdominal pressure* }\end{array}$ & $\begin{array}{c}\text { End of } \\
\text { experiment }\end{array}$ & $P^{*}$ & P\# \\
\hline Heart rate (beats/min) & $80 \pm 14$ & $80 \pm 19$ & $81 \pm 23$ & $85 \pm 28$ & $83 \pm 17$ & 0.916 & \\
\hline Cardiac output (ml/kg/min) & $101 \pm 24$ & & & & $96 \pm 20$ & & 0.371 \\
\hline $\begin{array}{l}\text { Systemic mean arterial } \\
\text { pressure ( } \mathbf{m m ~ H g})\end{array}$ & $87 \pm 16$ & $84 \pm 16$ & $91 \pm 18$ & $79 \pm 23$ & $84 \pm 16$ & 0.164 & \\
\hline Central venous pressure $(\mathrm{mmHg})$ & $8 \pm 3$ & & & & $8 \pm 3$ & & 0.808 \\
\hline $\begin{array}{l}\text { Pulmonary capillary occlusion } \\
\text { pressure (mmHg) }\end{array}$ & $8 \pm 3$ & & & & $7 \pm 2$ & & 0.615 \\
\hline Central temperature $\left({ }^{\circ} \mathrm{C}\right)$ & $37.3 \pm 1.2$ & & & & $37.5 \pm 1.3$ & & 0.337 \\
\hline
\end{tabular}


Table 2: Intraperitoneal, intraorgan and intravascular pressures $(\mathrm{mm} \mathrm{Hg})$ during the experiment.

\begin{tabular}{|c|c|c|c|c|c|c|}
\hline & Baseline & PEEP & $\begin{array}{c}\text { PEEP+external } \\
\text { abdominal pressure }\end{array}$ & $\begin{array}{c}\text { External abdominal } \\
\text { pressure }\end{array}$ & $\begin{array}{c}\text { End of } \\
\text { experiment }\end{array}$ & $P^{*}$ \\
\hline Intraperitoneal pressure & $6 \pm 1$ & $6 \pm 1$ & $9 \pm 2^{\# \#}$ & $9 \pm 2^{\# \#}$ & $5 \pm 1$ & $<0.001$ \\
\hline Urinary bladder pressure & $6 \pm 2$ & $7 \pm 2$ & $11 \pm 2^{\# \#}$ & $10 \pm 2^{\# \#}$ & $6 \pm 1$ & $<0.001$ \\
\hline Intragastric pressure & $6 \pm 2$ & $8 \pm 2$ & $11 \pm 2^{\# \#}$ & $10 \pm 2^{\# \#}$ & $6 \pm 2$ & $<0.001$ \\
\hline Inferior vena cava pressure & $11 \pm 4$ & $12 \pm 3^{\#}$ & $15 \pm 4^{\#}$ & $14 \pm 3^{\#}$ & $11 \pm 3$ & $<0.001$ \\
\hline Diastolic pulmonary artery pressure & $14 \pm 5$ & $16 \pm 4^{\#}$ & $17 \pm 5$ & $16 \pm 5^{\&}$ & $14 \pm 6$ & 0.003 \\
\hline
\end{tabular}

\section{Effects of PEEP and external abdominal pressure on intra-} abdominal pressures

PEEP had no effect on either intraperitoneal, intragastric or urinary bladder pressure (Table 2). All of these pressures increased with extraabdominal pressure, independent of the presence or absence of PEEP (Table 2).

\section{Effects of PEEP and external abdominal pressure on intra- vascular pressures}

PEEP was associated with an increase in both intravascular pressures (Table 2). Inferior vena cava but not pulmonary artery pressure increased during external abdominal pressure (Table 2).

\section{Comparison between absolute pressures and pressure changes}

Pressures and changes in pressures are compared in Figures 2, 3 and 4. Bias and limits of agreement were similar for the comparisons of absolute intraperitoneal pressure with intra-gastric $(-1,3$ to $-5 \mathrm{~mm} \mathrm{Hg})$ and urinary bladder pressure $(-1,2$ to $-5 \mathrm{~mm} \mathrm{Hg})$, but larger for the comparison between intra-peritoneal and inferior vena cava pressure $(-5,0$ to $-11 \mathrm{~mm} \mathrm{Hg})$. Bias (0 to $-1 \mathrm{~mm} \mathrm{Hg})$ and limits of agreement ( 3 to $-4 \mathrm{~mm} \mathrm{Hg}$ ) for pressure changes were similar for all three comparisons (Figures 2, 3, 4, lefthand side).

Correlations between intraperitoneal and intragastric, urinary bladder and inferior vena cava pressures (Figures $5,6,7)$, between urinary bladder and intragastric and inferior vena cava pressures (Figures 8 and 9), between intragastric and inferior vena cava pressures (Figure 10), and between inferior vena cava and pulmonary artery diastolic pressures (Figure 11) were all significant, although at varying degrees. Intraperitoneal and urinary bladder pressures correlated best $(r=0.730, p=0.01)$.

\section{Discussion}

The main finding of this study is that changing PEEP between 0 and $10 \mathrm{~cm} \mathrm{H}_{2} 0$ did not modify the pressure changes induced by external abdominal pressure intraperitoneally, in urinary bladder and stomach, and in inferior vena cava.

Normal IAP is $5-7 \mathrm{~mm} \mathrm{Hg}$ in non-morbidly obese patients [22]. During spontaneous respiration, inspiration and expiration are controlled by opposing activity of the diaphragm and abdominal muscles, which varies the shape of the pressurized abdominal cavity [23]. Accordingly, IAP does not increase. Situations in which IAP increases and pressure measurement has been advocated are non-operative management of blunt hepatic trauma [24], abdominal surgery [25], and abdominoplasty [26]. IAH at ICU admission is associated with severe organ dysfunction during the intensive care unit stay [27]. IAP, and especially abdominal perfusion pressure (mean arterial pressure - IAP), appears to be a clinically useful resuscitation endpoint and predictor of patient survival during treatment for IAH and ACS [2].

In the present study, median IAP values increased by approximately $5 \mathrm{~mm} \mathrm{Hg}$ and just reached the lower limit for the diagnosis of IAH [1]. In agreement with others, we found similar increases and decreases in intra-abdominal, intra-vesical and intra-gastric pressures with changing abdominal pressure [28-31].

In this model without lung injury, $10 \mathrm{~cm} \mathrm{H}_{2} \mathrm{O}$ PEEP had no significant effect on the relationship between the different pressures. In patients with acute lung injury, an increase and decrease in PEEP from 8-13 $\mathrm{H}_{2} \mathrm{O}$ and back did not change total hepato-splanchnic blood flow or the gastric mucosal-arterial $\mathrm{pCO}_{2}$ gradient [32]. In contrast, in patients without acute lung injury, perioperative appli- 


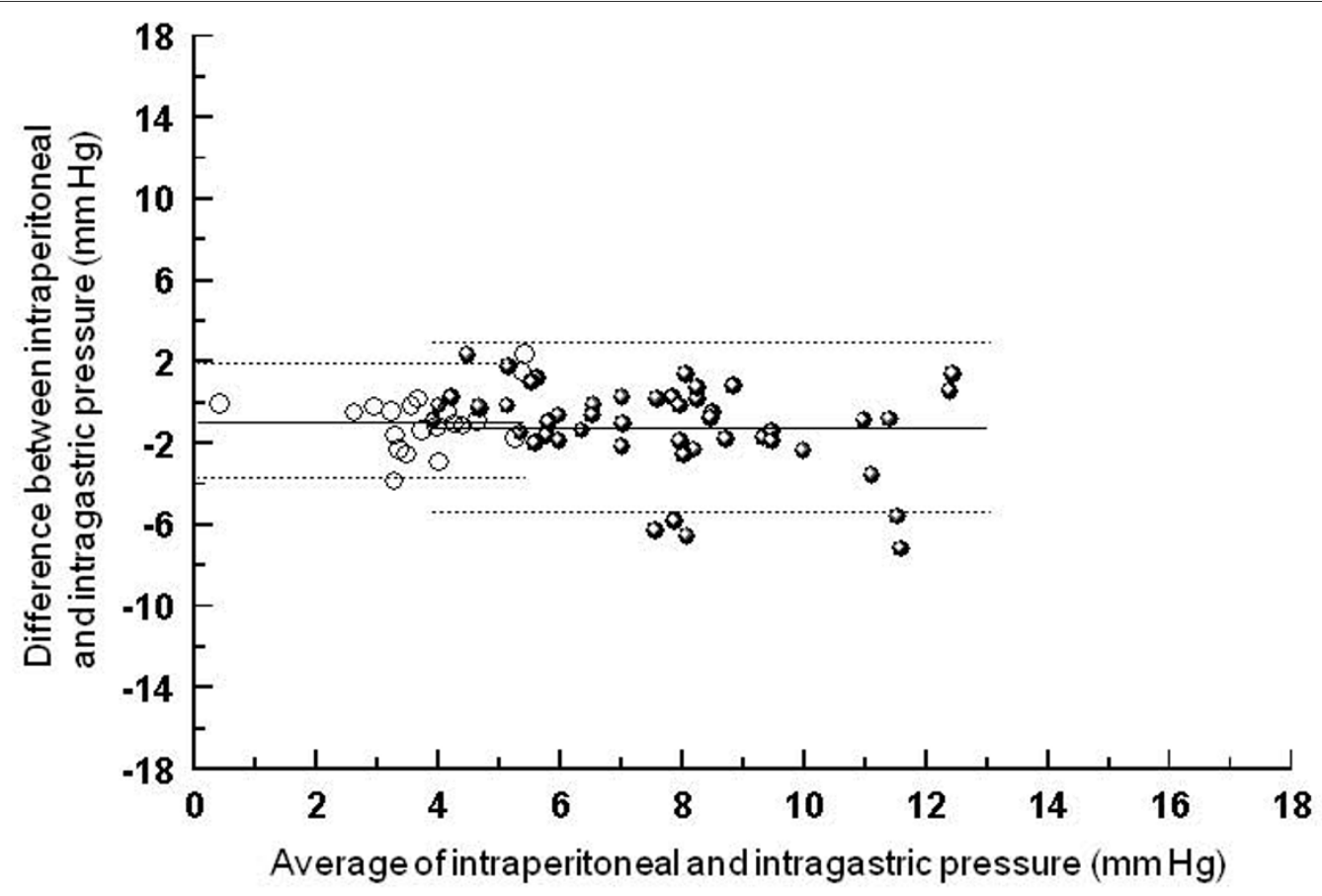

Figure 2 Bland-Altman graph for the comparison between intraperitoneal and intragastric pressure. Absolute values are displayed on the right side of the figure, and changes between baseline and external abdominal pressure with and without PEEP on the left side. Full lines represent bias (average of the differences), and dotted lines limits of agreement (+/- 1.96 SD).

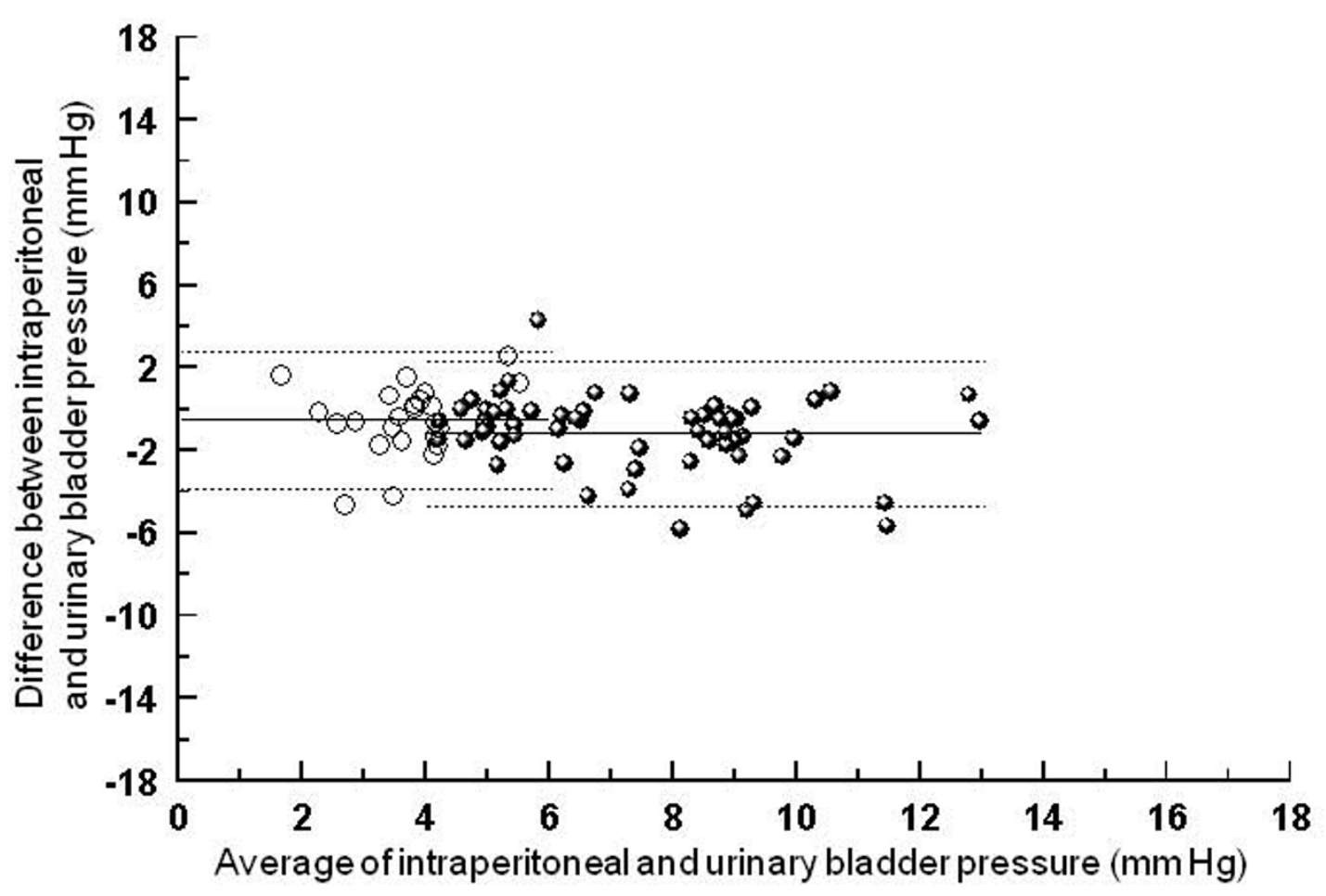

Figure 3 Bland-Altman graph for the comparison between intraperitoneal and urinary bladder pressure. Absolute values are displayed on the right side of the figure, and changes between baseline and external abdominal pressure with and without PEEP on the left side. Full lines represent bias (average of the differences), and dotted lines limits of agreement (+/- 1.96 SD). 


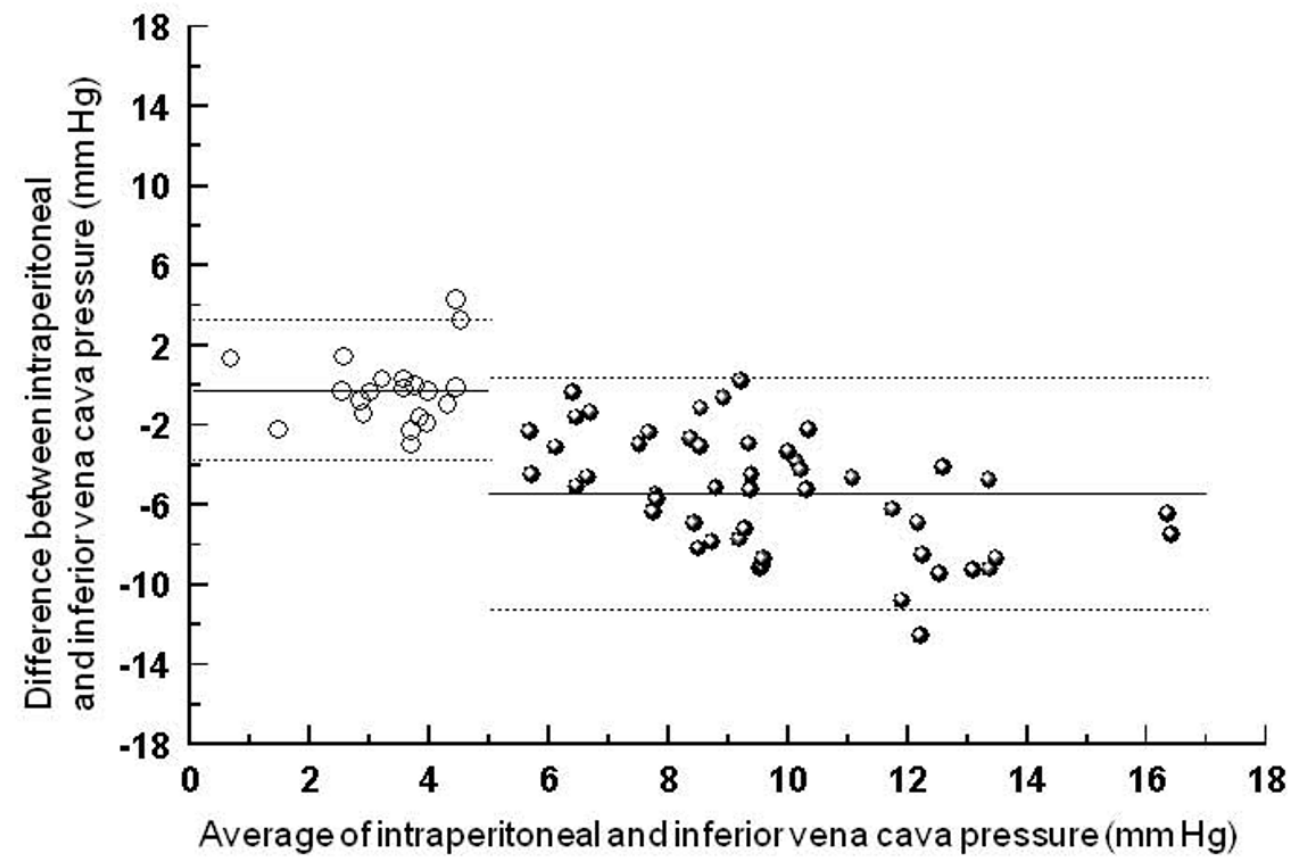

Figure 4 Bland-Altman graph for the comparison between intraperitoneal and inferior vena cava pressure. Absolute values are displayed on the right side of the figure, and changes between baseline and external abdominal pressure with and without PEEP on the left side. Full lines represent bias (average of the differences), and dotted lines limits of agreement (+/- 1.96 SD).

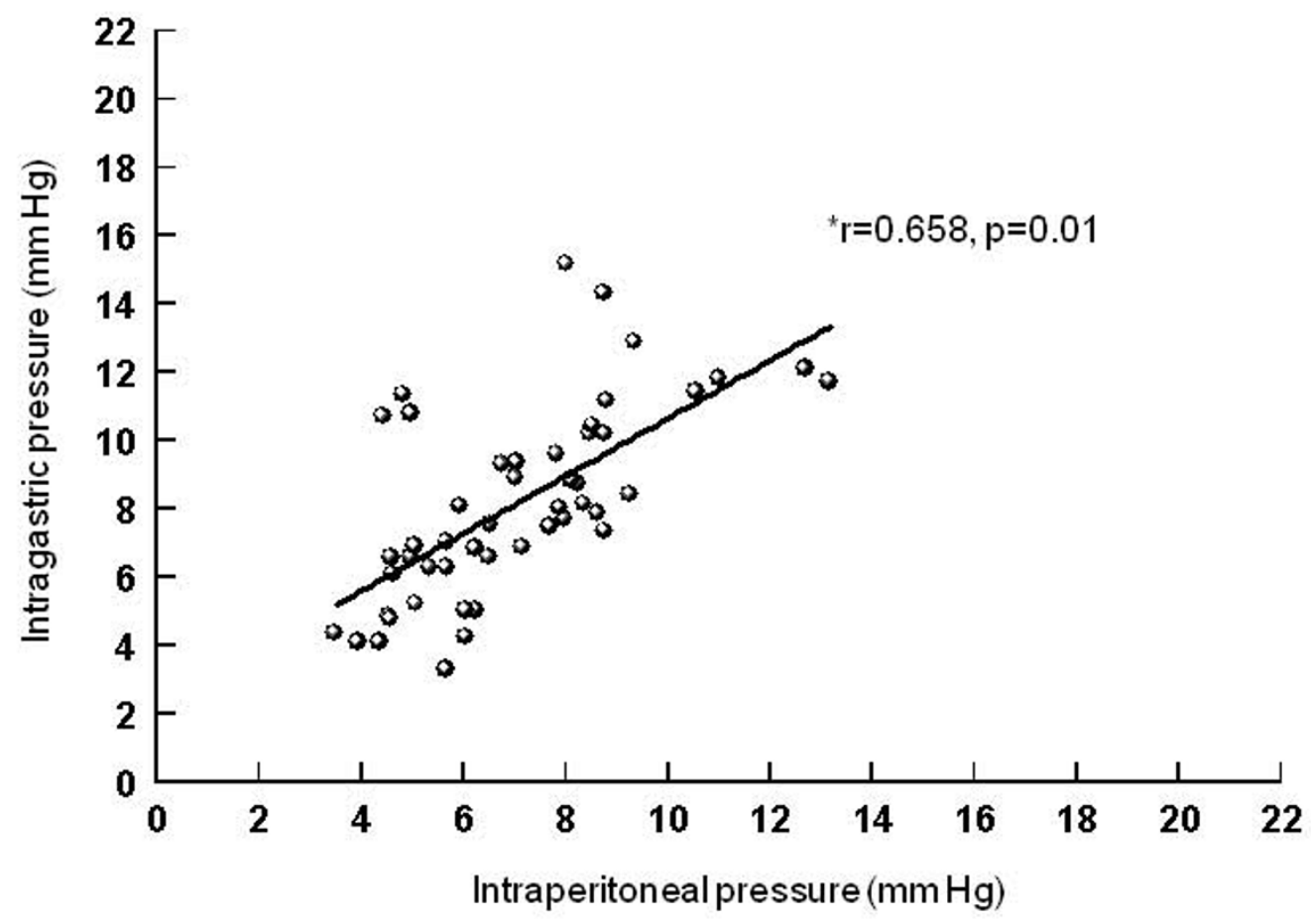

Figure 5 Correlation between intraperitoneal and intragastric pressure. *Pearson correlation. 


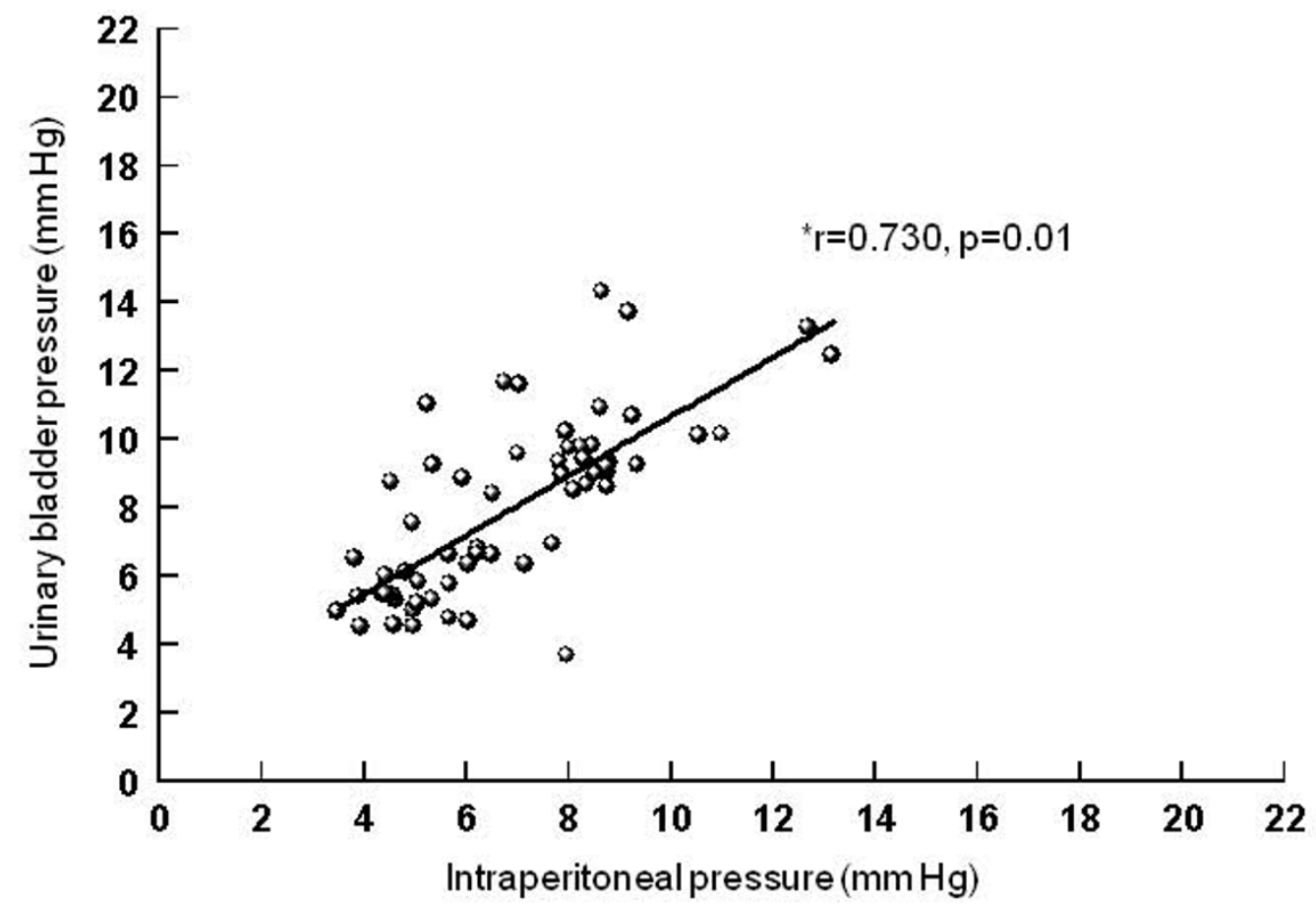

Figure 6 Correlation between intraperitoneal and urinary bladder pressure. *Pearson correlation.

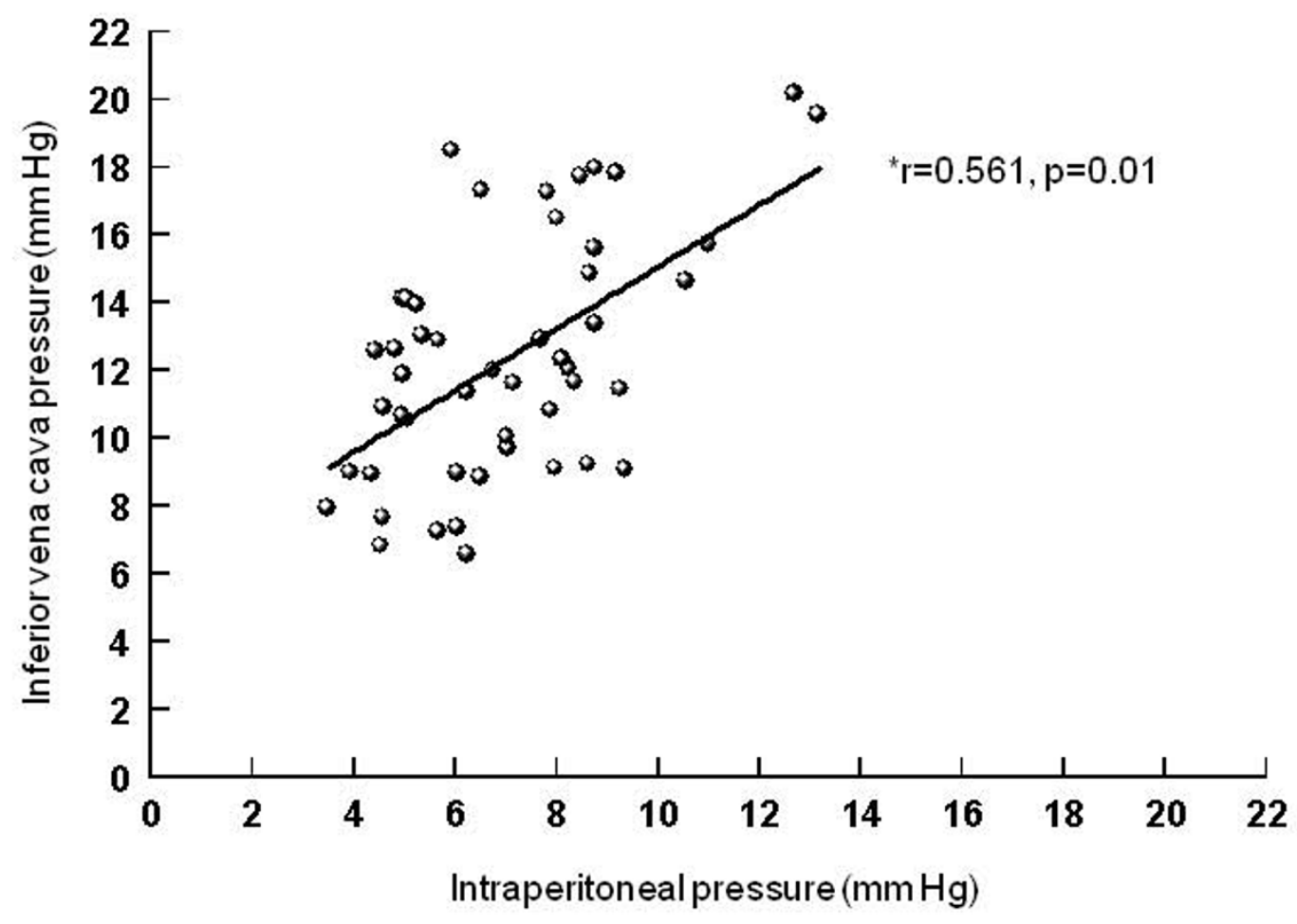

Figure 7 Correlation between intraperitoneal and inferior vena cava pressure. *Pearson correlation. 
cation of PEEP reduced splanchnic blood flow [33,34]. Application of PEEP has also been associated with marked reduction of total hepatic and portal venous blood flow in various experimental models, although the results are controversial [35-38]. It is possible that higher PEEP levels in our study would have increased IAP.

The present study was not designed to assess effects of intra-thoracic and IAP changes on perfusion. In pigs and dogs, the effect of low IAP (7-8 mm $\mathrm{Hg}$ ) on splanchnic perfusion is minimal, while at higher IAP values (14-16 $\mathrm{mm} \mathrm{Hg}$ ) portal blood flow decreases $[39,40]$.

Increases in IAP are also associated with increased respiratory pressures, and decreased lung compliance and gas exchange $[41,42]$. In our study, the increase in intra-thoracic pressure with increased abdominal pressure, if any, did not translate into a significant increase in pulmonary artery diastolic pressure. However, inferior vena cava pressure was higher than intraabdominal and intraorgan pressures. Some [40] but not all $[29,43]$ researchers found higher inferior vena cava pressures than IAP. A somewhat increased intraabdominal intravenous pressure seems physiological since a pressure gradient from inside to outside the vessel prevents vessel collapse, and a driving pressure is needed to generate flow to the heart. Interestingly, both the increase in IAP and application of PEEP resulted in an increase in intravascular pressure in the inferior vena cava. While the increase in intravascular pressure is the result of increased pressure around the vein in the former situation, it is a consequence of intravascular pressure transmission in the latter. This is evident from the unchanged IAP when only PEEP was applied. In humans with increased IAP, intravascular pressure in the inferior vena cava was not reflected by a similar increase in the superior caval vein pressure, due to a "waterfall" effect $[44,45]$. The increase in IAP evoked a transition of the abdominal venous compartment from a zone 3 to a zone 2 condition, presumably impairing venous return despite an increased pressure gradient between the abdominal and thoracic compartments [44]. This can be explained by decreased femoral vein blood flow [29]. Accordingly, PEEP and increased IAP seems to be the most crucial of the studied circumstances for venous return [46].

It has been shown that bolus administration of opioids and muscle relaxants can increase and decrease, respectively, IAP [47,48]. Furthermore, body position also has an effect on IAP [49]. Since we did not administer drugs as boli and kept the animals in supine position throughout the experiments, we can exclude such effects on our measurements. Nevertheless, when results of different

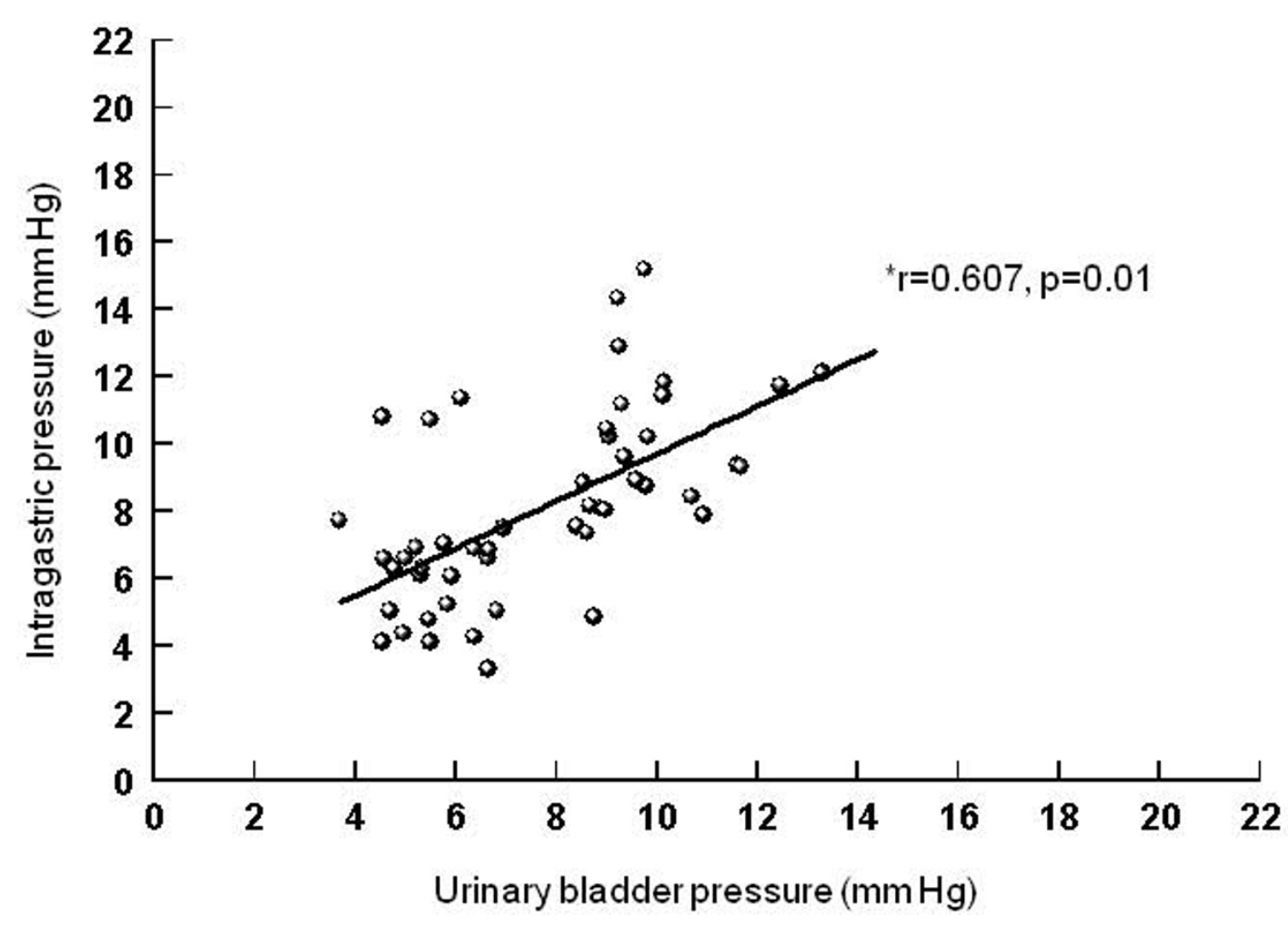

Figure 8 Correlation between urinary bladder and intragastric pressure. *Pearson correlation. 


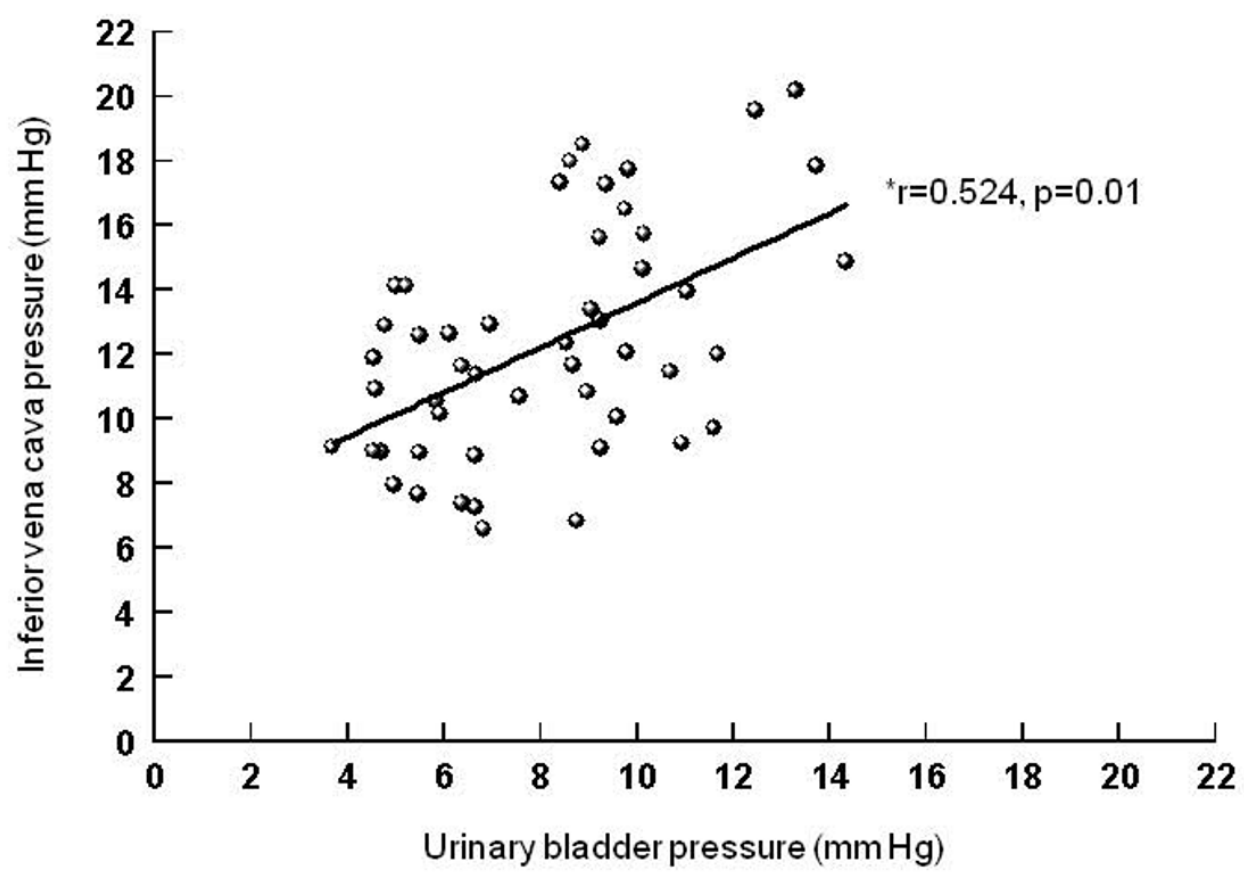

Figure 9 Correlation between urinary bladder and inferior vena cava pressure. *Pearson correlation.

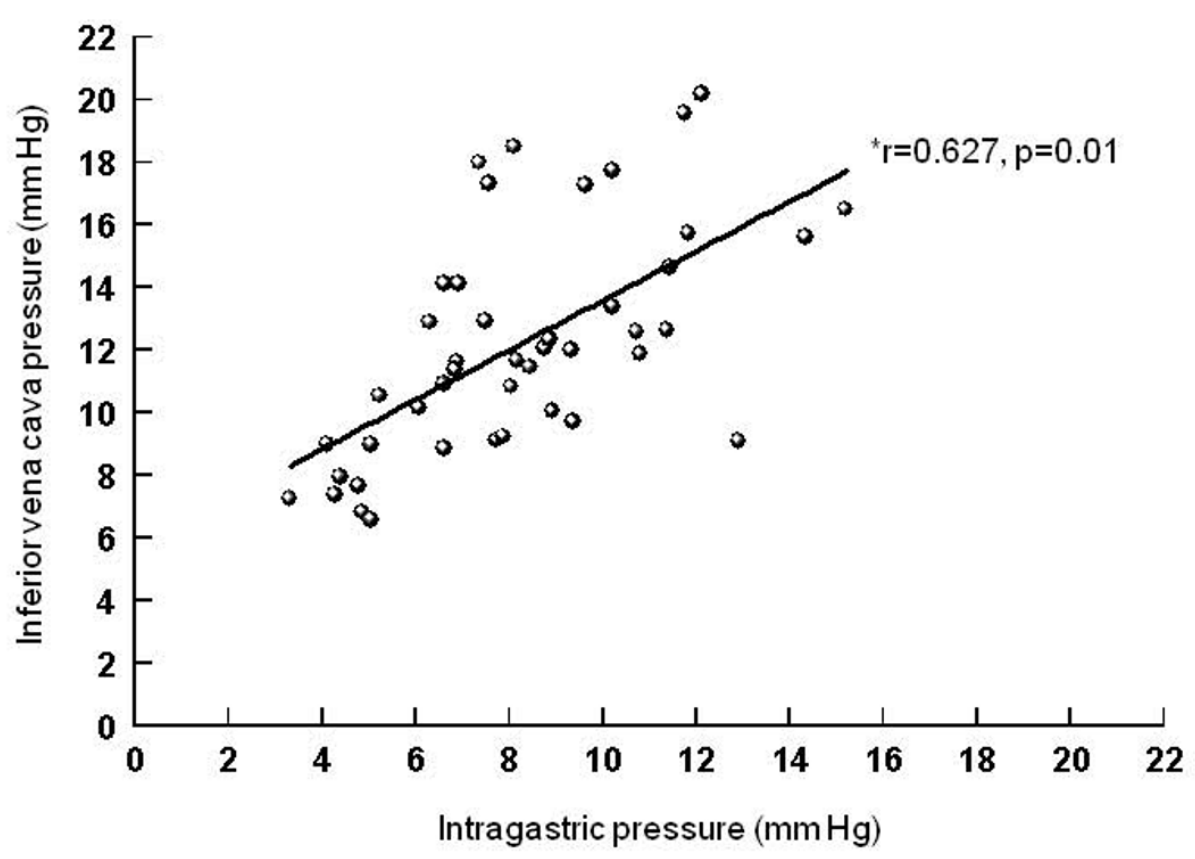

Figure 10 Correlation between intragastric and inferior vena cava pressure. *Pearson correlation. 


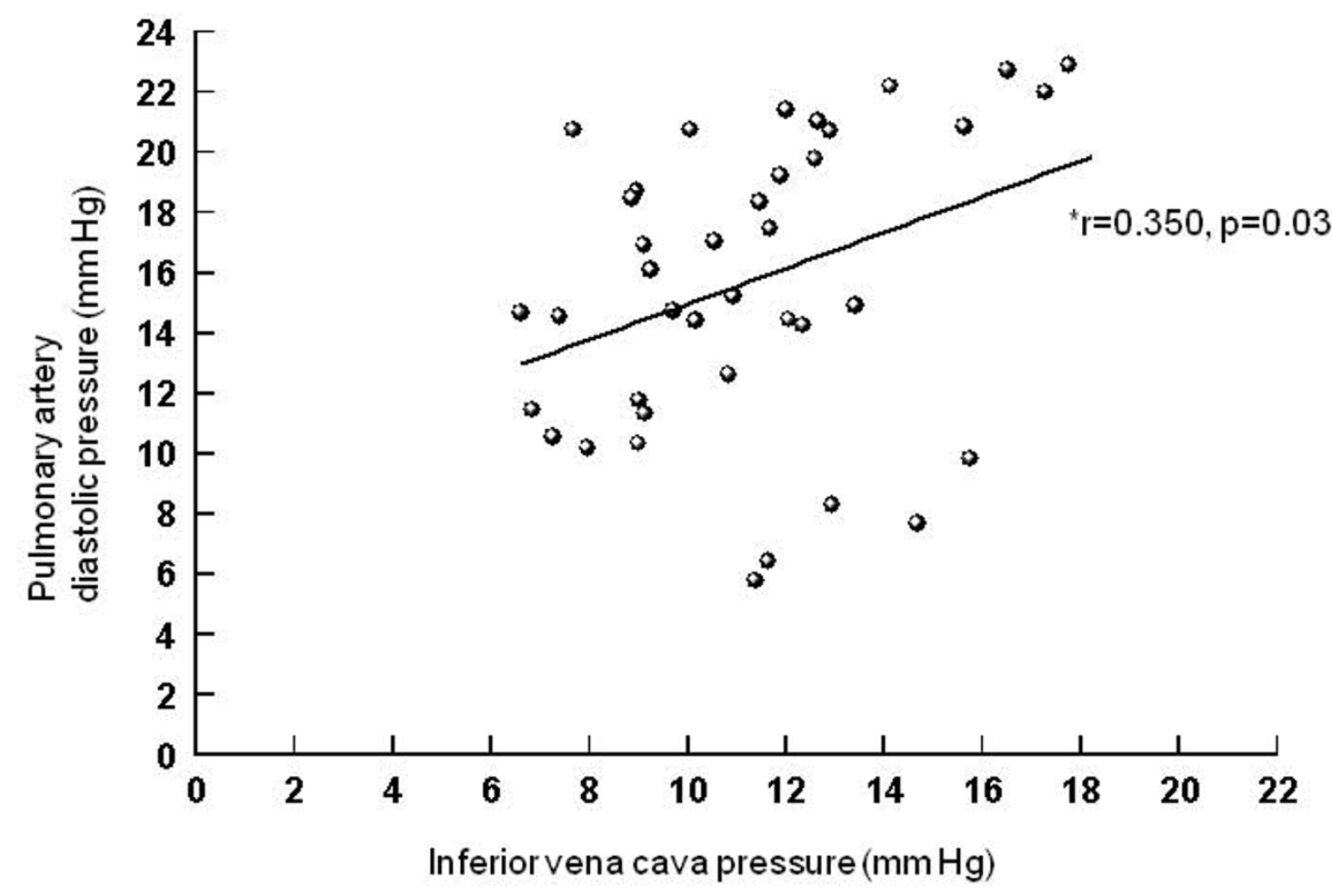

Figure 11 Correlation between inferior vena cava and pulmonary artery diastolic pressure. *Pearson correlation.

studies are compared, these aspects need to be considered.

A limitation of the experimental set-up is the use of external abdominal pressure, and the fact that it produced only moderate increases in the measured pressures. In humans, external abdominal pressure has been used to increase intraabdominal pressure [50]. There is considerable variation in the literature regarding the design for ACS in animals [51], and recommendations for research regarding IAH and ACS have been published only recently [52]. Consequently, our findings cannot necessarily be extrapolated to clinical situations with IAH. Nevertheless, it has been shown that increases in intra-gastric pressure or IAP of only a few $\mathrm{mm} \mathrm{Hg}$, e.g., during prone positioning $[53,54]$ or closure of laparotomy [55], can worsen gastric-mucosal perfusion, diuresis and arterial $\mathrm{pO}_{2}$.

Even if the changes in pressures were similar at the different locations, the absolute values differed. Such pressure differences may be real or the result of technical circumstances. As an example, instillation of $50 \mathrm{ml}$ into the pig's bladder may be too much, as in humans a maximal instillation volume of $20 \mathrm{ml}$ has been recommended. Gudmundsson et al. [29] demonstrated that the volume of fluid needed to increase porcine intra-vesical pressure by $2 \mathrm{~mm} \mathrm{Hg}$ varies widely and is dependent on IAP. On the other hand, Fusco et al. [56] showed that instillation of $50 \mathrm{ml}$ of fluid into the bladder improves the accuracy of the intra-vesicular pressure in measuring elevated IAP.

A further limitation is that we measured neither esophageal pressure nor the impact of tidal ventilation on changes in any of the measured pressures. Recent data suggest that the compliance of the abdominal wall has an impact on the magnitude of IAP changes during tidal ventilation [57].

\section{Conclusions}

Our data suggest that pressure changes induced by external abdominal pressure were not modified by changing PEEP between 0 and $10 \mathrm{~cm} \mathrm{H}_{2} 0$. Inferior vena cava pressure overestimated intra-peritoneal pressure.

\section{Competing interests}

The Department of Intensive Care Medicine has, or has had in the past, research contracts with Abbott Nutrition International, B. Braun Medical AG, CSEM SA, Edwards Lifesciences Services GmbH, Kenta Biotech Ltd, Maquet Critical Care AB, Omnicare Clinical Research AG, and Orion Corporation; and research \& development/consulting contracts with Edwards Lifesciences SA and Maquet Critical Care AB. The money is/was paid into a departmental fund; no author receives/received individual fees. The past contract with Edwards Lifesciences is unrelated to and did not influence the current study. 


\section{Authors' contributions}

SMJ and JT designed the study. SMJ, JJT and RP performed anesthesia, surgery, and carried out the experimental protocol. RK analyzed the data and drafted the manuscript. SJ performed the statistical analysis. SMJ and JT critically revised the manuscript. All authors read and approved the final manuscript.

\section{Acknowledgements}

We would like to thank Jeannie Wurz, Medical Editor, Dept. of Intensive Care Medicine, Bern University Hospital, for language and content editing of the manuscript. She is a permanent employee of the hospital.

Research was performed in the National Laboratory Animal Research Center of the University of Kuopio, Kuopio, Finland.

The study was supported through departmental funds from the Department of Intensive Care Medicine, Kuopio University Hospital, Kuopio, Finland, and from the Department of Intensive Care Medicine, Bern University Hospital and University of Bern.

\section{Author Details}

'Department of Intensive Care Medicine, University Hospital (Inselspital) and University of Bern, Bern, Switzerland and ${ }^{2}$ Department of Intensive Care Medicine, Kuopio University Hospital, Kuopio, Finland

Received: 27 August 2009 Accepted: 4 July 2010

Published: 4 July 2010

\section{References}

1. Malbrain ML, Cheatham ML, Kirkpatrick A, Sugrue M, Parr M, De Waele J, et al:: Results from the International Conference of Experts on Intraabdominal Hypertension and Abdominal Compartment Syndrome. I. Definitions. Intensive Care Med 2006, 32:1722-1732.

2. Cheatham ML, White MW, Sagraves SG, Johnson JL, Block EF: Abdominal perfusion pressure: a superior parameter in the assessment of intraabdominal hypertension. J Trauma 2000, 49:621-626.

3. Malbrain ML, Chiumello D, Pelosi P, Wilmer A, Brienza N, Malcangi V, et al:: Prevalence of intra-abdominal hypertension in critically ill patients: a multicentre epidemiological study. Intensive Care Med 2004, 30:822-829.

4. Barnes GE, Laine GA, Giam PY, Smith EE, Granger HJ: Cardiovascular responses to elevation of intra-abdominal hydrostatic pressure. $\mathrm{Am} J$ Physiol 1985, 248:R208-R213.

5. Ridings $\mathrm{PC}$, Bloomfield $\mathrm{GL}$, Blocher $\mathrm{CR}$, Sugerman $\mathrm{HJ}$ : Cardiopulmonary effects of raised intra-abdominal pressure before and after intravascular volume expansion. J Trauma 1995, 39:1071-1075.

6. Sugrue M, Balogh Z, Malbrain M: Intra-abdominal hypertension and renal failure. ANZ J Surg 2004, 74:78.

7. Gudmundsson FF, Gislason HG, Dicko A, Horn A, Viste A, Grong K, et al.: Effects of prolonged increased intra-abdominal pressure on gastrointestinal blood flow in pigs. Surg Endosc 2001, 15:854-860.

8. Diebel LN, Wilson RF, Dulchavsky SA, Saxe J: Effect of increased intraabdominal pressure on hepatic arterial, portal venous, and hepatic microcirculatory blood flow. J Trauma 1992, 33:279-282.

9. Ivatury RR, Porter JM, Simon RJ, Islam S, John R, Stahl WM: Intraabdominal hypertension after life-threatening penetrating abdominal trauma: prophylaxis, incidence, and clinical relevance to gastric mucosal pH and abdominal compartment syndrome. J Trauma 1998, 44:1016-1021.

10. Bloomfield $G L$, Ridings $P C$, Blocher $C R$, Marmarou A, Sugerman $H J$ J A proposed relationship between increased intra-abdominal, intrathoracic, and intracranial pressure. Crit Care Med 1997, 25:496-503.

11. Deeren DH, Dits H, Malbrain ML: Correlation between intra-abdominal and intracranial pressure in nontraumatic brain injury. Intensive Care Med 2005, 31:1577-1581.

12. Balogh Z, McKinley BA, Holcomb JB, Miller CC, Cocanour CS, Kozar RA, et al:: Both primary and secondary abdominal compartment syndrome can be predicted early and are harbingers of multiple organ failure. $J$ Trauma 2003, 54:848-859.

13. Ravishankar N, Hunter J: Measurement of intra-abdominal pressure in intensive care units in the United Kingdom: a national postal questionnaire study. Br J Anaesth 2005, 94:763-766.

14. Tiwari $A$, Myint $F$, Hamilton $G$ : Recognition and management of abdominal compartment syndrome in the United Kingdom. Intensive Care Med 2006, 32:906-909.
15. Malbrain ML: Is it wise not to think about intraabdominal hypertension in the ICU? Curr Opin Crit Care 2004, 10:132-145.

16. Kirkpatrick AW, Brenneman FD, McLean RF, Rapanos T, Boulanger BR: Is clinical examination an accurate indicator of raised intra-abdominal pressure in critically injured patients? Can J Surg 2000, 43:207-211.

17. Lee SL, Anderson JT, Kraut EJ, Wisner DH, Wolfe BM: A simplified approach to the diagnosis of elevated intra-abdominal pressure. $J$ Trauma 2002, 52:1169-1172.

18. Malbrain ML: Different techniques to measure intra-abdominal pressure (IAP): time for a critical re-appraisal. Intensive Care Med 2004, 30:357-371

19. De Potter TJ, Dits H, Malbrain ML: Intra- and interobserver variability during in vitro validation of two novel methods for intra-abdominal pressure monitoring. Intensive Care Med 2005, 31:747-751.

20. Valenza F, Chevallard G, Porro GA, Gattinoni L: Static and dynamic components of esophageal and central venous pressure during intraabdominal hypertension. Crit Care Med 2007, 35:1575-81.

21. Jakob SM, Tenhunen JJ, Laitinen S, Heino A, Alhava E, Takala J: Effects of systemic arterial hypoperfusion on splanchnic hemodynamics and hepatic arterial buffer response in pigs. Am J Physiol Gastrointest Liver Physiol 2001, 280:G819-G827.

22. De Keulenaer BL, De Waele JJ, Powell B, Malbrain ML: What is normal intra-abdominal pressure and how is it affected by positioning, body mass and positive end-expiratory pressure? Intensive Care Med 2009, 35:969-76.

23. Hodges PW, Gandevia SC: Changes in intra-abdominal pressure during postural and respiratory activation of the human diaphragm. J Appl Physiol 2000, 89:967-976.

24. Chen RJ, Fang JF, Chen MF: Intra-abdominal pressure monitoring as a guideline in the nonoperative management of blunt hepatic trauma. J Trauma 2001, 51:44-50.

25. Nguyen NT, Lee SL, Anderson JT, Palmer LS, Canet F, Wolfe BM: Evaluation of intra-abdominal pressure after laparoscopic and open gastric bypass. Obes Surg 2001, 11:40-45.

26. Talisman R, Kaplan B, Haik J, Aronov S, Shraga A, Orenstein A: Measuring alterations in intra-abdominal pressure during abdominoplasty as a predictive value for possible postoperative complications. Aesthetic Plast Surg 2002, 26:189-192.

27. Malbrain ML, Chiumello D, Pelosi P, Bihari D, Innes R, Ranieri VM, Del Turco M, Wilmer A, Brienza N, Malcangi V, Cohen J, Japiassu A, De Keulenaer BL, Daelemans R, Jacquet L, Laterre PF, Frank G, de Souza P, Cesana B, Gattinoni L: Incidence and prognosis of intraabdominal hypertension in a mixed population of critically ill patients: a multiple-center epidemiological study. Crit Care Med 2005, 33:315-22.

28. Yol S, Kartal A, Tavli S, Tatkan Y: Is urinary bladder pressure a sensitive indicator of intra-abdominal pressure? Endoscopy 1998, 30:778-780.

29. Gudmundsson FF, Viste A, Gislason H, Svanes K: Comparison of different methods for measuring intra-abdominal pressure. Intensive Care Med 2002, 28:509-514.

30. Balogh Z, Jones F, D'Amours S, Parr M, Sugrue M: Continuous intraabdominal pressure measurement technique. Am J Surg 2004, 188:679-684.

31. Risin E, Kessel B, Ashkenazi I, Lieberman N, Alfici R: A new technique of direct intra-abdominal pressure measurement: a preliminary study. Am J Surg 2006, 191:235-237.

32. Kiefer $P$, Nunes $S$, Kosonen $P$, Takala J: Effect of positive end-expiratory pressure on splanchnic perfusion in acute lung injury. Intensive Care Med 2000, 26:376-383.

33. Winso O, Biber B, Gustavsson B, Holm C, Milsom I, Niemand D: Portal blood flow in man during graded positive end-expiratory pressure ventilation. Intensive Care Med 1986, 12:80-85.

34. Bonnet F, Richard C, Glaser P, Lafay M, Guesde R: Changes in hepatic flow induced by continuous positive pressure ventilation in critically ill patients. Crit Care Med 1982, 10:703-705.

35. Fujita Y: Effects of PEEP on splanchnic hemodynamics and blood volume. Acta Anaesthesiol Scand 1993, 37:427-431.

36. Brienza N, Revelly JP, Ayuse T, Robotham JL: Effects of PEEP on liver arterial and venous blood flows. Am J Respir Crit Care Med 1995, 152:504-510.

37. Matuschak GM, Pinsky MR, Rogers RM: Effects of positive end-expiratory pressure on hepatic blood flow and performance. J Appl Physiol 1987, 62:1377-1383. 
38. Arvidsson D, Almquist $P$, Haglund U: Effects of positive end-expiratory pressure on splanchnic circulation and function in experimental peritonitis. Arch Surg 1991, 126:631-636.

39. Windberger UB, Auer R, Keplinger F, Längle F, Heinze G, Schindl M, Losert UM: The role of intra-abdominal pressure on splanchnic and pulmonary hemodynamic and metabolic changes during carbon dioxide pneumoperitoneum. Gastrointest Endosc 1999, 49:84-91.

40. Ishizaki Y, Bandai Y, Shimomura K, Abe H, Ohtomo Y, Idezuki Y: Safe intraabdominal pressure of carbon dioxide pneumoperitoneum during laparoscopic surgery. Surgery 1993, 114:549-54.

41. Gudmundsson FF, Heltne JK: Respiratory changes during prolonged increased intra-abdominal pressure in pigs. Acta Anaesthesiol Scand 2004, 48:463-468.

42. Banieghbal B, Gouws M, Davies MR: Respiratory pressure monitoring as an indirect method of intra-abdominal pressure measurement in gastroschisis closure. Eur J Pediatr Surg 2006, 16:79-83.

43. Harman PK, Kron IL, McLachlan HD, Freedlander AE, Nolan SP: Elevated intra-abdominal pressure and renal function. Ann Surg 1982, 196:594-597.

44. Giebler RM, Behrends M, Steffens T, Walz MK, Peitgen K, Peters J: Intraperitoneal and retroperitoneal carbon dioxide insufflation evoke different effects on caval vein pressure gradients in humans: evidence for the starling resistor concept of abdominal venous return. Anesthesiology 2000, 92:1568-1580.

45. Markou N, Grigorakos L, Myrianthefs P, Boutzouka E, Rizos M, Evagelopoulou $P$, et al: Venous pressure measurements in the superior and inferior vena cava: the influence of intra-abdominal pressure. Hepatogastroenterology 2004, 51:51-55.

46. Kotzampassi K, Paramythiotis D, Eleftheriadis E: Deterioration of visceral perfusion caused by intra-abdominal hypertension in pigs ventilated with positive end-expiratory pressure. Surg Today 2000, 30:987-992.

47. Drummond GB, Duncan MK: Abdominal pressure during laparoscopy: effects of fentanyl. Br J Anaesth 2002, 88:384-8.

48. De Laet I, Hoste E, Verholen E, De Waele JJ: The effect of neuromuscular blockers in patients with intra-abdominal hypertension. Intensive Care Med 2007, 33:1811-4

49. Cheatham ML, De Waele JJ, De Laet I, De Keulenaer B, Widder S, Kirkpatrick AW, Cresswell AB, Malbrain M, Bodnar Z, Mejia-Mantilla JH, Reis R, Parr M, Schulze R, Puig S, World Society of the Abdominal Compartment Syndrome (WSACS) Clinical Trials Working Group: The impact of body position on intra-abdominal pressure measurement: a multicenter analysis. Crit Care Med 2009, 37:2187-90.

50. Citerio G, Vascotto E, Villa F, Celotti S, Pesenti A: Induced abdominal compartment syndrome increases intracranial pressure in neurotrauma patients: a prospective study. Crit Care Med 2001, 29:1466-71.

51. Schachtrupp A, Wauters J, Wilmer A: What is the best animal model for ACS? Acta Clin Belg Suppl 2007, 1:225-32.

52. De Waele JJ, Cheatham ML, Malbrain ML, Kirkpatrick AW, Sugrue M, Balogh Z, Ivatury R, De Keulenaer B, Kimball EJ: Recommendations for research from the International Conference of Experts on Intraabdominal Hypertension and Abdominal Compartment Syndrome. Acta Clin Belg 2009, 64:203-9.

53. Kiefer P, Morin A, Putzke C, Wiedeck H, Georgieff M, Radermacher P: Influence of prone position on gastric mucosal-arterial PCO2 gradients. Intensive Care Med 2001, 27:1227-30.

54. Joshipura VP, Haribhakti SP, Patel NR, Naik RP, Soni HN, Patel B, Bhavsar MS, Narwaria MB, Thakker R: A prospective randomized, controlled study comparing low pressure versus high pressure pneumoperitoneum during laparoscopic cholecystectomy. Surg Laparosc Endosc Percutan Tech 2009, 19:234-240.

55. Schachtrupp A, Höer J, Töns C, Klinge U, Reckord U, Schumpelick V: Intraabdominal pressure: a reliable criterion for laparostomy closure? Hernia 2002, 6:102-7.

56. Fusco MA, Shayn Martin R, Chang MC: Estimation of intra-abdominal pressure by bladder pressure measurement: validity and methodology. J Trauma 2001, 50:297-302.

57. Sturini E, Saporito A, Sugrue M, Parr MJ, Bishop G, Braschi A: Respiratory variation of intra-abdominal pressure: indirect indicator of abdominal compliance? Intensive Care Med 2008, 34:1632-7.
Pre-publication history

The pre-publication history for this paper can be accessed here: http://www.biomedcentral.com/1471-230X/10/70/prepub

doi: $10.1186 / 1471-230 X-10-70$

Cite this article as: Jakob et al., Increasing abdominal pressure with and without PEEP: effects on intra-peritoneal, intra-organ and intra-vascular pressures BMC Gastroenterology 2010, 10:70

\section{Submit your next manuscript to BioMed Central and take full advantage of:}

- Convenient online submission

- Thorough peer review

- No space constraints or color figure charges

- Immediate publication on acceptance

- Inclusion in PubMed, CAS, Scopus and Google Scholar

- Research which is freely available for redistribution

Submit your manuscript at www.biomedcentral.com/submit
C BioMed Central 